\title{
The Importance of Quantitative Skill Sets Across Business Functions: An Appraisal of EMployer Expectations Versus Curriculum Emphasis in Schools of Business in the United States
}

\author{
Teodros Getachew
}

Teodros Getachew, Department of Finance, Providence College, 1 Cunningham Square, Providence, RI 02918. E-Mail: tgetache@providence.edu

\begin{abstract}
This paper examines, through a survey of alumni, whether distinct professions in the US value different subsets of those quantitative skill sets deemed important in business. It then investigates whether this pattern of emphasis corresponds to what is currently taught in Schools of Business in the United States.
\end{abstract}

Keywords: quantitative skill sets, problem solving, critical thinking, employment, business education.

DOI: http://dx.doi.org/10.15239/j.brcadvje.2018.03.01.ja01 


\section{INTRODUCTION}

Graduates of Business programs in the US often feel ill prepared for the work world in terms of critical competencies, and this fact is echoed in the sentiments expressed by prospective employers. The importance of quantitative studies in the business world is underscored by the fact that approximately half the decisions made by small businesses are of a quantitative nature (Taylor, 2008). A survey of employers (Casner-Lotto, 2006) on behalf of a consortium of private corporations, human resource management professionals and research and consulting organizations states that while $92 \%$ of the respondents rated critical thinking and problem solving as very important qualities in a prospective hire from a four-year college, only $27.6 \%$ rated their recent hires as "excellent" in this regard. In a similar vein, the National Leadership Council for Liberal Education and America's Promise (Bok, 2007) reports that $73 \%$ of employers advised colleges to place more emphasis on critical thinking and analytical reasoning, $70 \%$ on information literacy and the ability to be innovative and think critically, $64 \%$ on the ability to solve complex problems and $60 \%$ on the ability to work with numbers and understand statistics.

\section{LITERATURE REVIEW}

Given that the issue of the under-employment of college graduates has proven persistent (Vedder, Denhart, \& Robe, 2013), employers' expectations as well as their perceptions of the skill sets that students bring to the job are important determinants in the career success of graduates, and as such are an indirect measure of the relative success or failure of the education preparing them for the work world. This relationship is discussed in some detail in the context of the British labor market (Lowden, Hall, Elliot, \& Jon, 2011) and with respect to the US macro-economic setting (National Academy of Sciences, 2007; Hart Research Associates, 2010; Fogg, \& Harrington, 2011). Complementary to 
this research is that aimed at measuring and validating the competencies that are imparted through higher education (Conchado, Carot, \& Bas, 2015).

In Casner-Lotto, (2006), employers are asked to characterize recent graduates' readiness to work in terms of what they consider to be critical competencies. After identifying Critical Thinking/Problem Solving (92.1\%), Creativity/Innovation (81.0\%) and Information Technology $(81.0 \%)$ as the three most important competencies, they rated readiness in these areas excellent in only $27.6 \%, 21.5 \%$ and $46.3 \%$ of graduates respectively. In Mattern et al., (2014) most employers indicated that colleges should emphasize oral communication (89\%), critical thinking (81\%), complex problem solving (75\%), ethical decision making $(75 \%)$, teamwork $(71 \%)$ and innovation and creativity $(70 \%)$.

In a similar vein, a survey aimed at understanding which learning outcomes were believed by employers to be the most important in today's economy Hart Research Associates (2015) revealed that those rated as most important broke down as follows: $80 \%$ of employers rated the ability to apply knowledge and skills to real-world settings, $70 \%$ the ability to analyze and solve complex problems, $65 \%$ the ability to innovate and be creative, $60 \%$ staying current on changing technologies and their applications to the workplace and $56 \%$ the ability to work with numbers and understand statistics. In addition, $80 \%$ stated that it was important that recent graduates demonstrate the ability to apply learning to real-world settings. In the same paper, both students and employers, respectively, agree on the importance of overarching skills such as: critical thinking and analytical reasoning $(81 \%, 79 \%)$, the ability to analyze and solve complex problems $(70 \%, 73 \%)$, the ability to locate, organize and evaluate information from multiple sources $(68 \%, 73 \%)$, the ability to innovate and be creative $(65 \%, 69 \%)$, staying current on changing technologies and their application to the workplace $(60 \%, 68 \%)$ and the ability to work with numbers and understand statistics (56\%, 55\%). In Hart Research Associates (2013), 95\% of employers indicated a preference for hiring 
college graduates with innovative skills, while $93 \%$ said that a candidate's critical thinking, communication and complex problem-solving skills are more important than their major.

In a major Bentley University study (2014), business leaders rated hard and soft skills as equally important for success in the workplace, with a preference for recent college graduates with industry-specific skills over liberal arts graduates who may require training. A summary of surveys of consulting firms, small business owners and quantitative reasoning instructors (Taylor, 2008) identified algebra, mathematical modeling, basic statistics, tackling loosely-defined, messy problems, tracking down information, making realistic assumptions and communicating the findings as essential quantitative skills in business. In this regard, Hung (2006) discusses the role of well-designed problems in the teaching of problem solving skills and discusses a particular problem design model for doing so.

A survey of business school alumni from a small public university (Barrett \& Tolbert, 2014) identified scheduling and financial analysis as the quantitative techniques of greatest use among the respondents. This paper suggests that further study be done to assess the need for specific skills. In (Rosen, Weil, \& Zastrow, 2003) the following are identified as elements of quantitative literacy: facility with estimation, proportions and counting, ability to use information in graphs and charts and drawing inferences therefrom, recognizing patterns and appreciating complex interactions, mathematical modeling, a grasp of the importance of variability and checking hypotheses and identifying levels of rigor in inference. More particularly, Holtzman \& Kraft (2010) state that at least $50 \%$ of employers and alumni identified skills in budgeting, financial accounting and project management and forecasting as quantitative areas routinely used in the workplace with spreadsheet skills singled out as particularly important. In this regard Alam, Gale, Brown, \& Khan (2010) discuss the importance of human skills in project management and the degree of emphasis laid on these skills within higher education. 


\section{RESEARCH QUESTIONS}

As is evident from the literature review, the picture painted of desirable quantitative skills is a broad one. Given the breadth of expectations, universities serve their graduates by delivering skills that go beyond traditional boundaries (Bridgstock, 2011). What is not clear is where these boundaries lie, especially with respect to the extent to which different business functions (e.g. marketing versus accounting) may require different quantitative skill sets. Hence the first research question (RQ1) of this study is to investigate the importance of and the degree to which desired quantitative skill sets differ across business functions among professionals. The second research question (RQ2) is whether this difference in importance, if present, is reflected in the way quantitative skills are taught in different business school departments.

\section{METHOD}

This study is based on an online survey that was sent out to 3716 Providence College business alumni employed in a wide variety of professions (see Table 1 and Table 2 in the web appendix), of which 202 responded, a student survey sent out to 946 Providence College School of Business Sophomores, Juniors and Seniors of which 116 responded (see Table 3 in the web appendix), as well as on data gathered on fifteen US business programs regarding their quantitative skills teaching emphasis. The alumni survey asked respondents to assign twelve quantitative skills identified in literature as relevant to business (Holtzman \& Kraft, 2010; Barrett \& Tolbert, 2014) four levels of importance in terms of frequency of use in the workplace; rarely used, sometimes used, used most of the time and always used. These skills are, 1 . Budgeting and cost analysis, 2. Cash flow analysis, 3. Capital investment analysis, 4. Demand management, 5. Financial accounting, 6. Forecasting, 7. Logistics analysis/ planning, 8. Project evaluation, 9. Project management, 10. Quality management, 11. Statistical process control and 12. Market/stakeholder 
surveys. Corresponding to each profession among Accounting, Finance, Management and Marketing and each quantitative skill, the number of ratings for each level of frequency of use was determined from survey data. These numbers were then converted to proportions (see Tables 47 in the web appendix).

The twelve skills were then further classified into four, overlapping, quantitative skill classes (QSCs) as follows: Accounting_QSC (Budgeting and cost analysis, Cash flow analysis, Financial accounting), Finance_QSC (Cash flow analysis, Capital investment analysis, Financial accounting, Forecasting), Management_QSC (Demand management, Forecasting, Logistics analysis/planning, Project evaluation, Project management, Quality management, Statistical process control) and Marketing_QSC (Demand management, Forecasting, Market/stakeholder surveys). Fifteen business programs in US representing diverse program sizes and pedagogical approaches were chosen and for each of four departments within these programs (Accounting, Finance, Management, Marketing), the number of courses in which each of the four QSCs were taught was determined. These numbers were then converted to proportions (see Tables $8-11$ in the web appendix).

Finally, frequency data with respect to self-reported student familiarity levels with ten out of the twelve quantitative skills was gathered (Statistical Process Control and Stakeholder/Market Surveys were excluded as they were not part of the Providence College curriculum). These counts were then converted to proportions (see Tables 12-14 in the web appendix).

\section{RESULTS}

The statistical analysis sought to address the two research questions of this study by formally answering the following questions: 


\section{Preview Complete}

This completes the limited preview of this paper. Please visit the link below to purchase.

\section{Citation Information}

Getachew, Teodros. "The Importance of Quantitative Skill Sets Across Business Functions: An Appraisal of Employer Expectations Versus Curriculum Emphasis in Schools of Business in the United States." BRC Fournal of Advances in Education 3, no. 1 (2018): 1-13. http:// dx.doi.org/10.15239/j.brcadvje.2018.03.01.ja01

\section{Web APPE ndix}

A web appendix for this paper is available at: http://dx.doi.org/10.15239/ j.brcadvje.2018.03.01.wa01 